\title{
Management guidelines for the HCV and HIV co-infected adult: Recommendations of a multidisciplinary expert panel
}

S urvival time in those with the human immunodeficiency virus (HIV) and AIDS has increased dramatically with the evolution of effective antiretroviral therapy. Simultaneously, morbidity has shifted from that related to opportunistic infections to that related to complications of chronic diseases (such as hepatitis B and C), consequences of injection drug use, and malignancies such as lymphoma. The efficacy of treatment of the hepatitis $\mathrm{C}$ virus $(\mathrm{HCV})$ in the HIV-negative patient has improved with the use of combination therapy of interferon (IFN) and ribavirin. Consequently, treatment of the $\mathrm{HCV}$ and HIV (HCV/HIV) co-infected patient is now of increased relevance but is complicated due to the medical, social and drugrelated issues of the affected population. Many HCV/HIV co-infected patients are substance-dependent and often are dependent on more than one substance. Assessing and treating the addiction is an integral component of the approach to treatment, potentially improving adherence to and tolerance of antiviral therapy. Treating addictions before therapy may also minimize the risk of accelerating liver disease with continued alcohol use or reinfection with $\mathrm{HCV}$ after the completion of $\mathrm{HCV}$ treatment.

A multidisciplinary panel was convened at the request of Health Canada with the mandate of developing recommendations for the management of the co-infected patient. Funding was obtained from the Hepatitis C Division of Health Canada as part of the Hepatitis C Initiative.

Physicians with expertise in clinical investigation and patient care in the fields of HIV, HCV and addictions were invited to participate in the conference. Those physicians with expertise in education, guideline dissemination, clinical virology and family practice also participated. Affected individuals representing the hemophilia, HIV and HCV communities also contributed to the discussion and recommendations. Current published data were reviewed and critically evaluated by the relevant experts with brief presentations to the group. The main issues were discussed in small workshops, and the recommendations developed were presented to and revised by the larger group.

The recommendations focus on the diagnosis and treatment of the HIV- and HCV-coinfected patient. Detailed recommendations for the management of HIV, HCV and addictions are found in other relevant journals and guidelines. The recommendations are rated according to the strength and quality of the evidence (1). The written guideline document was reviewed by all of the panel members and by 46 other specialists in infectious diseases, gastroenterology, virology and hematology. All comments were reviewed and incorporated into the final manuscript. 


\section{EPIDEMIOLOGY, NATURAL HISTORY AND TREATMENT OF HIV}

More than 45,000 Canadians have been reported to be infected with HIV, the virus that leads to AIDS (2). Although men who have sex with men remain predominantly at risk for HIV infection in Canada, an increasing proportion of patients are infected through intravenous drug use (IVDU) and needle sharing with contaminated blood (2). Injection drug use is found disproportionately in certain urban cities to be a risk factor for HIV, and in Vancouver, it has now become the predominant risk factor for new cases of HIV. The HIV prevalence rates in Canadian injection drug users (3) are estimated to be $25 \%$ in Vancouver, $18 \%$ in Montreal, $20.5 \%$ in Ottawa-Hull, $8 \%$ in Toronto and $14 \%$ in Winnipeg (4). Injection drug use as a risk factor for HIV infection is increasing in certain subgroups, such as women, prisoners and aboriginals. In 1999, for $46.1 \%$ of all new cases of HIV in Canadian women, injection drug use was the primary risk factor (2). A survey of federal prison inmates in 1998 found that $33 \%$ were $\mathrm{HCV}$ infected, $2 \%$ were HIV infected and $24 \%$ reported a history of injection drug use (5). Of the cumulative AIDS cases in Canada, $14.4 \%$ were reported in aboriginals in 1999 compared with less than $1 \%$ in this ethnic group before 1990 (2).

Before the development of highly active antiviral therapy (HAART), the mean life expectancy of individuals with HIV infection was eight to 10 years (6). Since the introduction of HAART, the incidence of opportunistic infections, hospitalizations and HIV-associated mortality have decreased dramatically, although the mean survival time for patients since the introduction of HAART is currently unknown (7-11).

Although curing HIV is not yet possible, combination antiretroviral therapy has been the key to the success of HIV therapy. Improvements in outcome were initially attributed to antiretroviral combination therapy with two nucleoside reverse transcriptase inhibitors (NRTIs) together with one or two protease inhibitors $(12,13)$. However, more recent evidence has suggested that equivalent virological (HIV RNA levels) and immunological (CD4 cell) responses have been achieved, at least over the short term, with non-nucleoside reverse transcriptase inhibitors (NNRTIs) in combination with NRTI or triple NRTI-based regimens (14-16). Treatment is costly, however, and difficult to adhere to because of the large number of pills, frequent dosing schedules with specific food and water requirements, and frequent short and long term toxicities (ie, peripheral neuropathy, diarrhea, renal colic, lipodystrophy, etc), which may be dose limiting (17).

The appropriate time to initiate antiretroviral therapy remains controversial, and in a given patient, therapy must balance the prevention of immune damage and virological failure resulting from nonadherence or antiviral resistance with the quality of life related to adverse events from the drugs (18). Many guidelines based on expert opinion are available, but no clinical trial data are available to dictate the best time to initiate therapy (19-22). The most recent guidelines recommend that therapy should begin if the CD4 cell count decreases below $350 / \mu \mathrm{L}$ or if the HIV RNA levels increase above 5000 to 30,000 copies/mL $(19,20)$. The goal of treatment is to suppress viral replication as much as possible and for as long as possible, enabling stabilization or improvement in immune function and decreasing the risk of infectious complications. Although optimal responses (suppressing viral load to less than 50 copies $/ \mathrm{mL}$ ) are observed in approximately $60 \%$ to $80 \%$ of patients previously naive to therapy, the proportion responding to subsequent or salvage combinations and the durability of this response is lower due to problems with antiviral resistance, including cross-resistance within drug classes $(23,24)$.

\section{EPIDEMIOLOGY, NATURAL HISTORY AND TREATMENT OF HCV}

$\mathrm{HCV}$, an RNA virus, is transmitted from person to person by contaminated blood. Therefore, persons at risk include those who have been exposed to blood or blood products before the introduction of testing for anti-HCV (ie, 1990) and those who have been exposed to contaminated needles or equipment used for injection - either for illegal drug use, tattooing, body piercing or any other situation in which reusable needles are used. Sexual transmission of HCV does occur, but at a significantly lower rate than that of either hepatitis B or HIV (eg, less than $10 \%$ ) (25). Sexual transmission may be increased when there is mucosal damage related to trauma or sexually transmitted diseases. Maternal transmission of HCV is less than $7 \%$ unless there is co-infection with HIV; in these cases, the figure rises to almost $20 \%$ (26). Measured by antibody screening, the prevalence of HCV in Canadians is estimated to be approximately $0.8 \%$ (27); this figure is less when HCV RNA testing is used. In injection drug users, more than $80 \%$ are infected, with infection typically occurring within the first year of drug use.

Long term follow-up studies report that approximately $50 \%$ of children and young adults infected with HCV have persistent infection $(28,29)$. In those patients infected at an older age, more than $80 \%$ become chronically infected (30). Persistent infection is associated with chronic hepatitis, which can include inflammation (mild to severe) and/or fibrosis (none to cirrhosis). Progression is generally slow, occurring over several decades. Chronic HCV infection is now the most common indication for liver transplantation, because it is a common infection, and decompensated cirrhosis develops in about $20 \%$ to $30 \%$ of infected patients. Cirrhosis is complicated by hepatic decompensation and/or the development of hepatocellular carcinoma. The reported frequency of hepatic decompensation ranges from $25 \%$ at 10 years, as reported in Italy, to $25 \%$ at five years, as reported in the United States, after a diagnosis of cirrhosis is established $(31,32)$. In the western world, hepatocellular carcinoma complicates cirrhosis secondary to HCV in $1 \%$ to $4 \%$ of cases/year (31). Risk factors for more rapidly progressive disease include male sex, age older than 40 years at the time of HCV acquisition, daily alcohol consumption of more than $50 \mathrm{~g}$ /day (three to four drinks), obesity and immunosuppression, including co-infection with HIV $(33,34)$.

The current standard of care for chronic HCV (35) is treatment with a combination of subcutaneous interferon-alpha- $2 b$ 


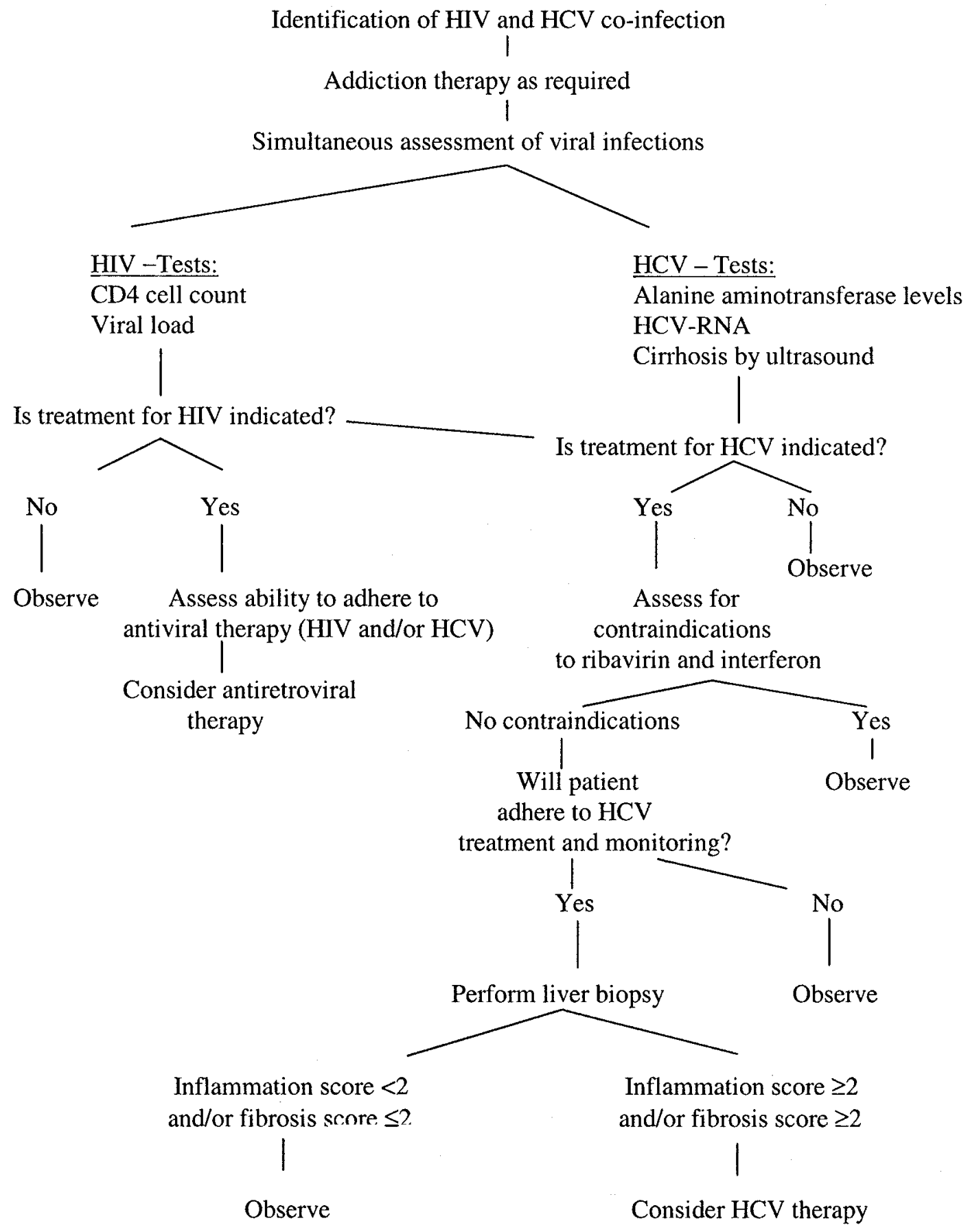

Figure 1) Algorithm for the management of human immunodeficiency virus (HIV) and hepatitis C virus (HCV) co-infected patients

(IFN $\alpha 2 b), 3,000,000 \mathrm{U}$ three times a week, and oral ribavirin, 1000 to $1200 \mathrm{mg} /$ day. Treatment is indicated for patients who, in an adequate liver biopsy, have more than minimal disease, ie, any inflammation grade 2 or higher (out of 4 ) and/or fibrosis stage higher than 2 (out of 4), according to METAVIR score (36). The equivalent Knodell scores are an activity score high- er than 6 and a fibrosis score of 3 or higher. The duration of therapy ranges from six months to one year depending on the pretreatment and viral genotype. Therapy is expensive and is associated with many side effects. Twelve per cent of those patients treated for six months discontinue treatment due to adverse events, as do $21 \%$ of those treated for one year. 
TABLE 1

Categories for quality of evidence

\begin{tabular}{ll}
\hline $\begin{array}{l}\text { Level of } \\
\text { evidence }\end{array}$ & Description \\
\hline $\mathrm{I}$ & $\begin{array}{c}\text { Evidence from at least one well designed, } \\
\text { randomized, controlled trial } \\
\text { Evidence from well designed, controlled trials } \\
\text { without randomization }\end{array}$ \\
II-2 & $\begin{array}{l}\text { Evidence from well designed cohort (prospective or } \\
\text { retrospective) or case-control studies, preferably } \\
\end{array}$ \\
fl-3 & Evidence from observational cross-sectional studies \\
& or dramatic results in uncontrolled experiments \\
III & Opinions of respected clinical experts or evidence \\
& from descriptive studies and case reports
\end{tabular}

Sustained virological response rates after treatment are less than $50 \%(37,38)$. Long term follow-up data showed that in $97 \%$ of patients treated for HCV with IFN $\alpha 2 b$ plus ribavirin who have a sustained virological response six months after the cessation of therapy, the serum HCV RNA remains undetectable (by qualitative Amplicor [Roche Diagnostics, Canada]) for up to two years. Longer follow-up data are not available (39). Long term follow-up studies following the successful treatment of HCV with IFN monotherapy for up to six years indicate that the lack of detectable HCV RNA in serum is associated with a lack of progression of liver disease, including the resolution of inflammation and the stability of fibrosis on liver histology (40-42). A sustained virological response is also associated with a decreased risk of developing hepatocellular carcinoma (43). Nonspecific subjective symptoms reported by patients with $\mathrm{HCV}$ infection improve when there is a sustained virological response to therapy $(44,45)$.

\section{IMPACT OF CO-INFECTION WITH HIV AND HCV}

HIV and HCV share the same transmission routes, and coinfection with these two viruses is common (46). This coinfection is especially prevalent in persons who acquired HIV through the transfusion of contaminated blood or blood products, such as patients with hemophilia or injection drug users. The immunodeficiency caused by HIV infection appears to accelerate the course of HCV (47-54). The impact of treating either virus on the natural history of the co-infected patient remains speculative. Chronic liver disease and hepatocellular carcinoma related to $\mathrm{HCV}$ are increasingly common causes of death in those with HIV, because HIV patients have decreased mortality and increased life expectancy with HAART (55). Consequently, attention has focused on the management of these two viruses in the coinfected patient. It has been recommended that patients with stable HIV be considered for the treatment of HCV. However, the potential hepatotoxic effects of antiretroviral therapy may be enhanced in the co-infected patient, with a negative impact on liver disease due to $\mathrm{HCV}(56,57)$. Further, because HCV pathogenesis depends on a host immune response, improvements in immunity following the introduction of
TABLE 2

Categories for strength of recommendations

\begin{tabular}{ll}
\hline Category & $\begin{array}{c}\text { Description of evidence for or against recommendation } \\
\text { for the use of a diagnostic test, treatment or intervention }\end{array}$ \\
\hline A & Good evidence to support recommendation for use \\
B & Moderate evidence to support recommendation for use \\
C & Poor evidence to support recommendation for or against use \\
D & Moderate evidence to support recommendation against use \\
E & Good evidence to support recommendation against use \\
\hline
\end{tabular}

HAART may result in a flare-up of HCV-related liver disease $(58,59)$. Finally, the optimal duration of treatment for HCV in the co-infected patient is unknown.

\section{SPECIAL ISSUES FOR THE MANAGEMENT OF THE CO-INFECTED PATIENT}

Management of the patient with HCV/HIV co-infection frequently requires consideration of the treatment of three diseases - not only HIV and HCV, but also addiction-related problems. Without adequate functional control of addiction issues, it is unlikely that treatment for either HIV or HCV will be optimal. There are treatment-related concerns, such as a decreased ability to adhere to or tolerate the adverse effects of the antiviral therapy, a risk of progressive liver disease from continued alcohol use, or reinfection with HCV through continued unsafe needle use after treatment (60-63). The subcutaneous use of IFN could serve as a conditioned cue for a relapse into needle use and addictive behaviours. There are also special issues in education specifically targeted to this group, as well as access to care and treatment. Issues of confidentiality related to HIV infection may require particular sensitivity when working with certain subgroups, such as prison inmates and aboriginals.

\section{IDENTIFICATION OF THE CO-INFECTED PATIENT}

Because of the overlapping risk groups (injection drug users, people with hemophilia, blood transfusion recipients), co-infection should be considered in all patients diagnosed with either HIV or HCV infection. Counselling guidelines and patient information concerning the meaning of test results are required. Upon diagnosis of HCV and/or HIV, in addition to referral to the appropriate physician(s) for care, the patient should be made aware of community organizations that can provide support and further information. Figure 1 outlines management strategies for the HCV/HIV co-infected patient. Also note that Table 1 describes the categories for the quality of evidence and Table 2 describes the categories for the strength of a particular recommendation. Ranking for a recommendation, where appropriate, follows a recommendation in brackets.

\section{Recommendations}

- All HIV-infected patients should have an HCV antibody test (hepatitis C serology) (III A).

- Some HIV-infected individuals may have a negative $\mathrm{HCV}$ antibody test despite co-infection. This is rare 
with the current assays used for HCV (64). Patients who have unexplained abnormal alanine aminotransferase levels (ALT) or who are at high risk (eg, hemophiliacs, injection drug users) should have a polymerase chain reaction (PCR) Amplicor qualitative test for HCV RNA if HCV serology is negative (III B).

- HCV-infected patients should have HIV testing (ELISA screening and Western blot if the ELISA is positive) as appropriate for risk (eg, all those who have acquired HCV through injection drug use, contaminated needles, blood or blood products, as well as those who have other risk factors for HIV, ie, men who have sex with men, and those who have had unprotected sexual intercourse with an individual from an endemic country, multiple sexual partners, a previous sexually transmitted disease, a known HIV-positive partner, etc). This screening needs to be performed before the initiation of therapy for $\mathrm{HCV}$ (III A).

- HIV testing must be performed within the context of appropriate pre- and post-test counselling (III A) (65).

- If the patient is HIV- or HCV-negative and appropriate risk reduction strategies are not adhered to, repeat testing at intervals is recommended (III A).

\section{COMPREHENSIVE MANAGEMENT OF THE CO-INFECTED PATIENT}

Address substance use issues: To ensure optimal management of the viral infections, substance use issues must be addressed initially or at least concurrently (66). This is necessary to:

- maximize the potential for adherence to antiviral treatment and follow-up;

- minimize the progression of the disease (eg, alcohol accelerates HCV progression);

- prevent $\mathrm{HCV}$ reinfection in $\mathrm{HCV}$ treatment responders whose virus has been eradicated (previous infection does not confer immunity);

- enable the patient to appreciate the complexity of and the commitment necessary for complicated antiviral treatment regimens and follow-up;

- assist in preparing the individual to cope with the side effects of treatment (eg, the influenza-like symptoms associated with IFN treatment could simulate opioid withdrawal states); and

- minimize the risk of HCV/HIV treatments worsening or destabilizing a concurrent addiction (eg, the trigger effect of IFN injections, or the unmasking or worsening of coexisting depression, which has a higher incidence in those with substance dependence).

\section{Recommendations}

- Comprehensive addictions assessment for anyone with a history of injection drug use (III A).

- Screening for the presence of alcohol disorders (eg, the CAGE questions) should be performed (III A).

- Screening of all patients for mood disorders should be completed (III A).

- The patient should be referred to an addictions specialist if they continue to have addiction problems that should be managed (III A).

- Ongoing participation in an addiction treatment program for patients with addictions or at risk for addiction should be recommended. The intensity of treatment is determined by the level of recovery achieved by the individual (III A).

Address alcohol use: Alcohol use (more than $50 \mathrm{~g} /$ day) accelerates the course of liver disease in patients with HCV infection $(33,34)$.

\section{Recommendation}

- Patients with co-infection should abstain from alcohol intake or minimize intake to less than $50 \mathrm{~g} /$ day. Abstinence is preferable and is essential for those with a history of alcohol abuse. One standard drink contains $13.6 \mathrm{~g}$ of alcohol and is equivalent to one bottle $(355 \mathrm{~mL})$ of beer ( $5 \%$ alcohol), $150 \mathrm{~mL}$ of wine ( $10 \%$ to $12 \%$ alcohol), $90 \mathrm{~mL}$ of fortified wine (16\% to $18 \%$ alcohol) or $45 \mathrm{~mL}$ of liquor ( $40 \%$ alcohol). Fifty grams of alcohol is contained in 3.6 standard drinks (II-3 A).

Assess patient for other hepatic viral infections: Co-infected patients should be assessed for susceptibility to hepatitis A and $\mathrm{B}(35,67)$.

\section{Recommendations}

- All co-infected patients should be evaluated for infection and immunity to hepatitis A (hepatitis A immunoglobulin $\mathrm{G}$ ) and hepatitis B (hepatitis B surface antigen and hepatitis $B$ antibody if the hepatitis B surface antigen is negative). Immunize patients who are not immune to hepatitis A or hepatitis B. Postvaccination monitoring of antibody response (hepatitis B surface antibody) is not required (II B).

- Discuss the risk of transmission of one or both infections. All co-infected patients should be made aware that transmission of $\mathrm{HCV}$ from person to person is enhanced by co-infection with HIV (III C).

\section{DEVELOP AN HCV PLAN}

Before considering therapy for $\mathrm{HCV}$ (see Figure 1 for management strategies of the $\mathrm{HCV} / \mathrm{HIV}$ co-infected patient), the natural history of co-infection, the nature of treatment, the 
complexity of follow-up, and the potential risks and benefits of treatment need to be explained to the patient. This requires an explanation by informed medical personnel, in a language and at an educational level appropriate to the individual, respecting cultural differences. Provision for access to the necessary expertise, and the appropriate clinical setting with available medical care (physical, psychological and social) and therapy must be made for optimal treatment success.

For some patients, it is more appropriate to treat HIV first, while in others, HIV may not require immediate therapy, and HCV is treated first. This depends on the stages of the two infections.

The most effective therapy currently available for the treatment of chronic hepatitis $\mathrm{C}$ is IFN $\alpha 2 \mathrm{~b}$ combined with ribavirin $(37,38)$. Treatment with IFN monotherapy is less effective than IFN combined with ribavirin $(36,37)$. Ribavirin monotherapy has no effect on serum HCV RNA levels (68). Recent trials of pegylated IFNs indicate that these long acting IFN monotherapies are almost as effective as the combination of IFN and ribavirin $(69,70)$, although the two treatments have not been compared directly. Pegylated IFNs are not currently licensed for use in Canada. Trials of pegylated IFNs combined with ribavirin are currently ongoing in HIVnegative and co-infected patients (71). The need for only weekly administration of the pegylated IFNs may improve adherence in hard-to-reach populations or in those who require direct observation.

\section{Recommendation}

- Patients who are candidates for HCV therapy should receive a combination of IFN $\alpha 2 b$ and ribavirin for 24 to 48 weeks, depending on the genotype of $\mathrm{HCV}$ with which they are infected. Those with genotype 1 should be treated for 48 weeks, and those with genotype 2 or 3 should be treated for 24 weeks (II-2 B).

The co-infected patient should be evaluated concerning his or her eligibility for HCV therapy before further diagnostic testing to characterize the extent of liver disease is performed (72). If the patient is not a candidate for drug therapy because he or she has contraindications to the use of either IFN or ribavirin (Table 3), or if he or she is unwilling to consider therapy, further invasive diagnostic tests do not need to be performed.

For HIV-negative, HCV-infected patients, therapy can be considered in those who have no absolute contraindications and who have relative contraindications that can be managed. There is no reason to believe that the approach in patients co-infected with HIV should be different.

There is no reliable, noninvasive test to determine which patients require therapy for HCV. Although the ALT level is the best measure of liver cell destruction, mean ALT values are similar for those with mild and severe liver disease, and the ALT level cannot be used to select patients for therapy (73). There is no noninvasive test to measure the degree of
TABLE 3

Contraindications to ribavirin or interferon (IFN) therapy

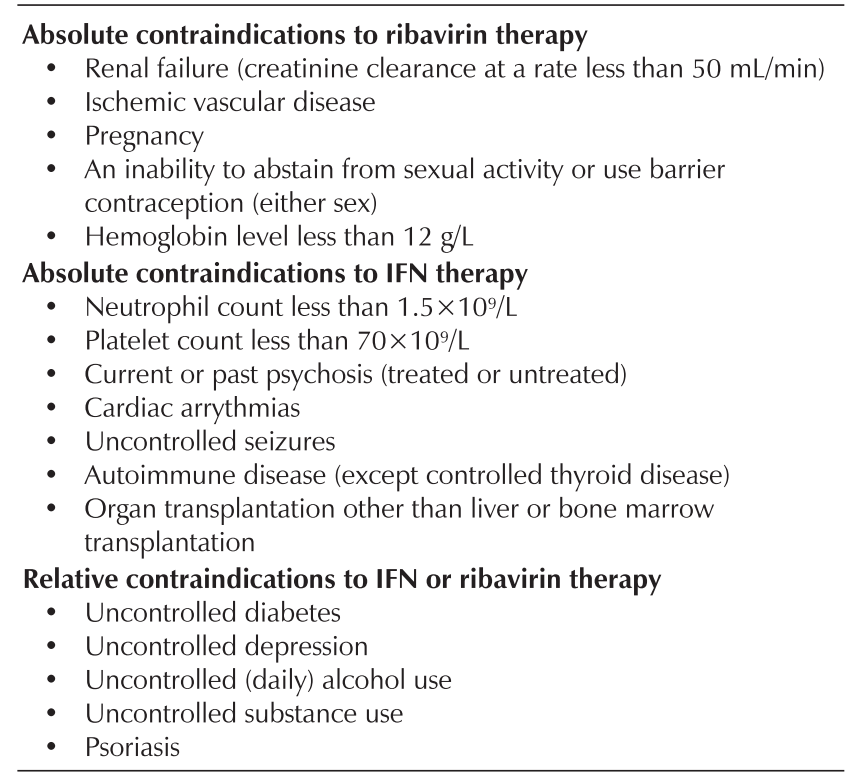

liver fibrosis. The quantitative HCV RNA level is not a reliable indicator of the extent of liver damage (74-76).

Further evaluation to determine whether therapy is needed can be considered in those patients who have persistently elevated serum ALT levels over a period of six months and in those who have no absolute contraindications to either IFN or ribavirin therapies. HIV-negative patients with normal ALT levels should not be considered for the treatment of $\mathrm{HCV}$ (34). Although patients with mild inflammation and/or fibrosis may respond better to treatment than patients with more advanced liver disease, treatment is associated with considerable toxicity, and the sustained virological response rate remains less than $50 \%$ in treated patients. Because these patients also have a slow rate of progression, treatment is generally deferred, and the extent of the liver disease is monitored at intervals with liver biopsy (35). It is unknown whether the risk to benefit ratio is different in co-infected patients with normal ALT than in those with only $\mathrm{HCV}$ infection.

\section{Recommendations}

- Co-infected patients with normal ALT levels should have the levels monitored every three months (III B).

- Co-infected patients with persistently abnormal ALT levels over a six-month period should be further evaluated for $\mathrm{HCV}$ treatment (II-3 C).

- Antiviral therapy is not recommended for patients with chronic $\mathrm{HCV}$ infection who have persistently normal ALT levels (II-3 C).

Abnormalities on liver biochemical tests are common in persons with HIV, especially in those on antiretroviral therapy. An increased ALT value is not necessarily due to the $\mathrm{HCV}$ infection. 


\section{Recommendation}

- Co-infected patients with abnormal ALT levels over a six-month period should have a qualitative HCV RNA PCR assay. Only patients with a positive assay should be further evaluated for HCV therapy. A patient who tests positive for anti-HCV and negative for HCV RNA, and who has an elevated ALT level, should have their HCV RNA test repeated at one year (III C).

The final decision concerning therapeutic intervention is made by the treating physician in combination with the patient, and generally is based on the results of the examination of a recent liver biopsy (35). However, there is controversy as to whether the liver biopsy is essential. Studies have shown that liver biopsy is the only way to assess the extent of the liver disease; it may also occasionally demonstrate disease other than $\mathrm{HCV}(77)$ and can be safely performed in patients with coagulation disorders (78-81). A recent cost-effectiveness study and its accompanying editorial suggested that liver biopsy was not required in HIV-negative patients $(82,83)$. This study cannot be extrapolated to the co-infected patient given the high prevalence of abnormal liver biochemistry in patients with HIV that is not related to HCV.

Because of side effects, some of which may be common with HCV treatment, and because the overall efficacy of $\mathrm{HCV}$ treatment remains at less than $50 \%$, it is not recommended that all patients chronically infected with HCV undergo therapy. For HCV-positive, HIV-negative patients, therapy should be considered in those who have more than minimal disease, ie, at least moderate inflammation and/or fibrosis (inflammation and fibrosis scores of 2 or higher according to the METAVIR scoring system). It has been demonstrated that the rate of progression to fibrosis is increased in those with co-infection (4753). However, it is unknown whether co-infected patients with lesser degrees of fibrosis and/or inflammation should be considered for treatment.

\section{Recommendations}

- In co-infected patients being considered for $\mathrm{HCV}$ therapy, a baseline abdominal ultrasound, international normalized ratio (INR) and complete blood count should be performed (III B).

- If the ultrasound does not demonstrate obvious cirrhosis and the patient consents, a liver biopsy is recommended to stage the extent of liver disease, as long as there are no contraindications to biopsy (eg, factor VIII inhibitors present) (III B).

- In patients with normal coagulation, cohort studies have demonstrated a $0.1 \%$ risk of hemorrhage and $0.01 \%$ risk of death from liver biopsy $(84,85)$. Because these risks are increased in patients with any coagulation disorder, a transjugular approach, which does not perforate the liver capsule, should be considered for liver biopsy in these patients
(III C). For patients with hemophilia, the patients' hematologist should be consulted to determine whether coagulation factor replacement therapy is recommended. Patients with hemophilia should, at least, have coagulation factors replaced to $75 \%$ to $100 \%$ before the procedure and maintained for $48 \mathrm{~h}$. Where appropriate, patients with increased bleeding risks should be monitored overnight. All patients should be sent home with clear instructions as to what to do if they develop any untoward symptoms after the procedure.

- The liver biopsy needs to be of adequate size (three to five portal tracts) and interpreted by an experienced pathologist (III A).

- The Canadian Consensus Guidelines recommend that HCV treatment be given to patients who have evidence of progressive liver disease. Patients with more than minimal disease, ie, at least moderate fibrosis and/or inflammation, are candidates for therapy (activity and fibrosis scores of 2 or higher according to the METAVIR scoring system) (III A).

- No recommendation can be made for HCV therapy of co-infected patients with lesser degrees of inflammation and/or fibrosis (III D). A repeat biopsy should be considered after three to five years in those in whom the initial biopsy showed minimal disease, ie, activity and/or fibrosis scores less than 2 according to the METAVIR scoring system (III C).

- Currently, antiviral therapy is not recommended for patients with chronic HCV patients who have decompensated cirrhosis (INR greater than 1.3, elevated conjugated bilirubin, ascites, hepatic encephalopathy and/or variceal hemorrhage) (II-3 B).

Responses to therapy for $\mathrm{HCV}$ are lower in those with higher HCV RNA levels and those with genotype $1(37,38)$.

\section{Recommendations}

- Before initiating therapy for HCV, HCV genotyping should be performed (35) (II-2 A).

- Patients having HCV genotype 1 should be treated for 48 weeks (35) (I A).

Monitoring HCV therapy: If the patient is both suitable for $\mathrm{HCV}$ antiviral therapy and requests anti-HCV therapy, treatment can be initiated. The side effects of treatment are maximal during the first two months. Hence, it is advised that treatment be started at a time when the patient's social and work conditions are stable and not excessively demanding. Patients need to understand that they must make themselves readily available for frequent blood tests and visits to the treating physician or nurse for assessment of side effects during therapy. 


\section{SIDE EFFECTS OF COMBINATION THERAPY AND WHAT SHOULD BE MONITORED}

Side effects of IFN: IFN causes influenza-like symptoms, eg, headaches, fever, muscle aches and chills, which generally are maximal during the first week of therapy and diminish thereafter (86). IFN affects the mood of most patients undergoing therapy, and patients and family need to be warned that this therapy is associated with irritability and sometimes overt depression. The patient may not always volunteer the severity of the mood disorder associated with antiviral therapy; it may be necessary to interview the patient's partner and/or other household contacts. Other side effects of IFN include thinning of hair, diarrhea, and worsening of psoriasis and/or lichen planus. If the patient is diabetic, the diabetes may become more difficult to control, and if there is thyroid dysfunction, control of thyroid disease may be lost. De novo thyroid disease and hyperglycemia may develop during IFN therapy. IFN depresses the bone marrow, causing the white blood cell count, particularly the absolute neutrophil count, to fall and occasionally inducing thrombocytopenia. Patients with cirrhosis are most likely to suffer bone marrow suppression because of their superimposed hypersplenism. Leukopenia puts the patient at risk of infection; in patients with cirrhosis, infection may occur spontaneously even in the absence of leukopenia. Low platelets may also be a result of immune thrombocytopenia related to either the HIV or HCV infection; hemorrhage secondary to IFN-induced thrombocytopenia is unusual.

\section{Recommendations}

- To reduce influenza-like symptoms, the patients should take their medication at night. Regular strength acetaminophen, in appropriate doses, may be used to reduce this side effect. Nonsteroidal anti-inflammatory agents should be avoided in patients with significant liver disease, eg, cirrhosis (III B).

- Patients must be monitored for the signs and symptoms of depression. Concurrent anti-depressant therapy is advocated in those patients who become depressed or who are suffering from depression at the time that antiviral therapy is being considered. Patients who develop severe depression or suicidal ideation should be referred for psychiatric consultation and/or follow-up (III B).

- Patients with a history of substance dependence will need additional monitoring, support and counselling with regard to the risk of depression and/or addiction relapse. Close collaboration with the patient's addictions treatment provider is strongly encouraged (III B).

- Treatment must be discontinued if diffuse psoriasis occurs (III B).

- Regular monitoring of blood sugar and thyroid stimulating hormone is essential (III B).
- IFN dose reduction is required when the absolute neutrophil count falls below $1.0 \times 10^{9} / \mathrm{L}$ and IFN must be stopped should the absolute neutrophil count fall below $0.5 \times 10^{9} / \mathrm{L}$ (III A). In patients with cirrhosis, a fall in the absolute neutrophil count may be associated with an increased risk of sepsis. All patients should be advised to report any symptoms of infection immediately, and undergo the appropriate investigations and antibiotic therapy as indicated.

- Complications secondary to thrombocytopenia are less common. It is not usually necessary to reduce the dose unless the platelet count falls to very low levels, eg, less than $40 \times 10^{9} / \mathrm{L}$ (III A).

Side effects of ribavirin: The most common side effect of ribavirin is hemolysis, which occurs in at least one-third of those receiving treatment (87). On occasion, the hemoglobin levels may fall by 2 to $3 \mathrm{~g} / \mathrm{L}$ in a very short period of time, which is often associated with the onset of sudden fatigue. Hemolysis can be so severe as to necessitate a blood transfusion. Nevertheless, low grade hemolysis persists throughout therapy, so the side effects of combination therapy may considerably limit a patient's physical activity. Therapy with ribavirin is also associated with a dry cough, skin rashes, and sometimes pruritus and insomnia.

\section{Recommendations}

- The hemoglobin levels and reticulocyte counts must be monitored for the side effects of ribavirin. Dose reduction of ribavirin is necessary when the hemoglobin level drops below $10 \mathrm{~g} / \mathrm{L}$ (III C).

- Adequate intake of water (more than $3 \mathrm{~L} /$ day) is suggested to reduce the symptoms of cough and rash (III C).

- Ribavirin is teratogenic and should not be administered in pregnancy (III B).

Efficacy of IFN and ribavirin therapy in chronic HCV: The desired response to therapy is to be unable to detect HCV in serum (using qualitative testing with a lower limit of detection of 100 copies $/ \mathrm{mL}$ ) at the end of treatment and six months after the cessation of treatment. A sustained virological response is observed in up to $41 \%$ of HIV-negative patients with chronic $\mathrm{HCV}$ who are treated with a combination of IFN $\alpha 2 \mathrm{~b}$ and ribavirin for up to 48 weeks $(37,38)$. The sustained virological rates are considerably higher for those patients infected with genotype 2 or $3 ; 60 \%$ to $64 \%$ of these patients may have a sustained loss of detectable HCV RNA. of those infected with genotype 1, sustained virological response rates are low (10\% with 24 weeks of therapy and $27 \%$ with 48 weeks of therapy), particularly in those with a baseline viral load greater than $2,000,000$ copies/mL or $850,000 \mathrm{IU} / \mathrm{mL}$. Efficacy rates for those with genotype 1 but a lower viral load are somewhat improved (32\% with 24 weeks of therapy and $33 \%$ with 48 weeks of therapy) $(37,38)$. 
Nevertheless, the recommendation is to treat all patients infected with genotype 1 for 48 weeks (35). The number of patients with HCV/HIV co-infection who have received either IFN or IFN plus ribavirin is small. To date, the end of treatment responses appear to be similar to those achieved by patients who are HIV negative (88-92). The data on sustained responses are limited. Whether there truly is a higher relapse rate, as suggested in some cohorts, is unclear. A sustained virological response in HIV-negative patients is nearly always accompanied by a sustained normalization of ALT levels and an improvement in hepatic histology, chiefly the necroinflammatory component $(93,94)$. Improved hepatic histology may be seen in some patients without a sustained virological response, but whether this histological improvement is sustained for the long term after the cessation of therapy in the presence of persistent viremia remains undetermined (95). Long term trials of therapy (four years) are ongoing in patients who do not have a sustained virological response to assess the value and safety of a partial response.

\section{Recommendations}

- Response to therapy should be evaluated using qualitative testing for HCV RNA by PCR six months after starting therapy, at the end of treatment and six months after the cessation of therapy (the lower limit of detection is approximately $50 \mathrm{IU} / \mathrm{mL}$ by Amplicor) (I A).

- A liver biopsy at the end of treatment is not indicated (II-2 E).

- If the HCV RNA remains positive at 24 weeks, treatment should be discontinued (II-2 A).

Patients who are not eligible for or fail to respond to antiviral therapy may be considered for liver transplantation if the liver disease becomes decompensated, provided the HIV infection is stable. However, the effectiveness of liver transplantation in this setting needs to be determined.

\section{Recommendation}

- Stable, controlled HIV co-infection should not be an absolute contraindication to liver transplantation (III C).

\section{HIV PLAN}

Treatment of HIV infection should follow the guidelines recommended for HIV-infected patients who do not have $\mathrm{HCV}$. Initiation of therapy should be guided by immune status (CD4 cell counts), viral replication levels (HIV RNA), and the patient's willingness and ability to adhere to combination antiretroviral therapy (19-22). Combinations based on triple reverse transcriptase inhibitors, non-nucleoside inhibitors and protease inhibitors are all acceptable therapies $(19,20)$. For patients with addiction issues, simple combination therapies directly observed at street clinics, needle exchange centres or methadone treatment centres should be considered.
Should the treatment of HIV infection precede, follow or be concurrent with therapy for HCV? There is no available evidence on which to base recommendations for the timing of HIV treatment in co-infected patients. Until such data are available, all co-infected patients should be encouraged to initiate HCV therapy within the context of a cohort or randomized controlled clinical trial, where available.

The theoretical basis for the initial management of $\mathrm{HCV}$ is the concern for the hepatotoxicity of many of the antiretroviral agents currently in use, which could be exacerbated with HCV $(56,57)$. However, it remains unclear whether prior therapy for $\mathrm{HCV}$ can decrease subsequent toxicity to HIV medications. In addition, the immune restoration associated with HAART therapy could lead to an increase in the immunological response against $\mathrm{HCV}$ and potential worsening of the liver disease $(58,59)$. In contrast, the beneficial effects of various HIV treatments have been demonstrated in controlled clinical trials, and, where indicated, HIV treatment should not be deferred pending HCV treatment.

\section{Recommendations}

- In general, HIV should be addressed before $\mathrm{HCV}$ and managed according to guidelines (I A). Once the patient has been stabilized on combination antiretroviral therapy, consideration should be given to initiating $\mathrm{HCV}$ therapy (III C).

- For those patients with stable HIV infection not requiring immediate therapy (ie, CD4 cell counts greater than $350 / \mathrm{mL}$ and HIV RNA levels less than 5000 to 30,000 copies $/ \mathrm{mL}$ ), consideration should be given first to the treatment of HCV (III C).

- A treatment holiday in HIV therapy before the start of HCV therapy to decrease drug toxicity cannot be recommended at this time (III C).

- Because of the therapeutic complexity and the overlapping toxicities associated with the treatment of HIV and HCV, the initiation of both treatments at the same time should be avoided (III C). The patient should be stabilized on one treatment before the second is introduced.

What are the preferred antiretroviral agents for the co-infected patient? All antiretroviral agents have the potential to cause hepatotoxicity. Certain drugs have been associated with an increased risk of hepatotoxicity in the co-infected patient and should be used with caution, especially when there is evidence of baseline liver dysfunction.

\section{Recommendation}

- Full dose ritonavir and nevirapine should be avoided, or used with caution, in the co-infected patient (II-3 B). 
Should patients with co-infection be monitored more frequently? The initiation of HAART has been associated with hepatic decompensation and/or increases in serum ALT levels in $\mathrm{HCV} / \mathrm{HIV}$ co-infection $(58,59)$. The mechanism of toxicity and the natural history of abnormalities in liver biochemical tests, in the presence or absence of HCV, is unknown. The role of immune restoration is speculative. The relationship of abnormalities in liver transaminases or hepatic decompensation to lipodystrophy, mitochondrial toxicity and hepatic steatosis is unknown but potentially important.

No recommendations can currently be made concerning the adjustment of doses of antiretroviral agents in the presence of liver abnormalities.

Co-infected patients should be monitored closely for the signs and symptoms of hepatic dysfunction. No recommendation can be made concerning at what specific ALT level antiretroviral agents should be discontinued.

No data are available to make a recommendation concerning whether the patient can be rechallenged with the same antiretroviral agent or the same class of antiretroviral agents after toxicity resolves.

Should NRTIs be discontinued when ribavirin is used? NRTIs are taken up into host cells and triphosphorylated into active agents by cellular kinases. Azidothymidine (zidovudine) and $\mathrm{d} 4 \mathrm{~T}$ (stavudine) are analogues of thymidine, and dideoxycytidine and 3TC (lamivudine) are analogues of cytidine. Ribavirin is a guanosine analogue that also requires phosphorylation to an active form by cellular kinases. In vitro, ribavirin can competitively inhibit the thymidine kinase required for the phosphorylation of zidovudine and possibly other agents in this class $(96,97)$. Ribavirin, in vitro, can also inhibit the metabolism of dideoxyinosine, resulting in increased concentrations of this agent and, theoretically, potentiation of the antiviral activity. The clinical relevance of these in vitro observations remains uncertain. No significant variation in HIV replication was observed in a recent study of 'combination therapy' in a co-infected population (98).

\section{Recommendations}

- There are insufficient clinical data to avoid or select specific agents of the NRTI class during concurrent therapy with ribavirin because of concerns of competition for phosphorylation (III C).

- Until more data are available, monitoring the HIV viral replication levels one month after the initiation of treatment for $\mathrm{HCV}$ is warranted. Nonspecific increases in HIV RNA levels may be observed at this point. If HIV RNA levels are increased at one month after the initiation of therapy, the testing of HIV RNA levels should be repeated two months after the initiation of therapy for $\mathrm{HCV}$. If they remain increased, modification of antiretroviral therapy or $\mathrm{HCV}$ therapy should be considered (III C).
Should certain antiretroviral agents be avoided during concurrent therapy of $\mathrm{HCV}$ ?

Recommendation

- Because ribavirin and IFN can cause toxicities that overlap with those of certain antiretroviral agents, concurrent use should be undertaken with caution and careful monitoring (III C). For example, myelosuppression occurs with zidovudine, hydroxyurea and IFN; in addition, depression occurs with efavirenz and IFN.

Changes to the agents used for antiviral combination therapy or prophylaxis against opportunistic infection may need to be made before the initiation of $\mathrm{HCV}$ treatment, if additive toxicities are anticipated.

\section{THE SETTING FOR MANAGEMENT OF THE CO-INFECTED PATIENT}

The initial assessment can take place in the primary care setting. It is important to ensure that all virological tests, medical imaging and pathology are performed in centres with the expertise to ensure the reliability and reproducibility of test results. Once a co-infected patient is identified, the patients should, ideally, be referred to a centre where patients have access to experts in addiction management (where appropriate), HIV and HCV $(99,100)$. In isolated or rural areas, communication may be via satellite clinics or telephone consultation. Although input by specialist physicians into the management strategy is mandatory, specially trained nurse practitioners or trained and appropriately funded primary care physicians could be responsible for ongoing care. The physician experts need to be readily accessible for input into the decision-making and the management of complications.

For patients with addiction problems, the provision of addiction-related care and education should be taken, where possible, to the client and linked to existing facilities, such as street clinics, methadone clinics or needle exchange sites. This will improve acceptance, minimize clinic visits and improve adherence. In these settings, addiction, HIV and HCV management at one site is preferable. In certain circumstances, simplifying the HIV regimen, combined with managing methadone and directly observing therapy, may be required. Ongoing education on risk reduction strategies needs to be structured to overcome language and cultural barriers. For aboriginal people, cultural differences and preferences for native remedies need to be recognized and integrated into the treatment plan.

\section{RESOURCE AND FUNDING ISSUES}

The management of co-infected patients is extremely complex. Access to management teams of the appropriate expertise is essential to optimize outcomes. Careful attention to the evaluation process (Figure 1) is necessary to ensure that appropriate patients receive therapy; to minimize drug adverse events, interactions and toxicities; and to ensure that the social, psychological and physical needs of patients are met, not only before, but also during and after therapy. Management 
of co-infected patients requires not only the availability and the appropriate use of drugs, but also laboratory facilities for monitoring treatment effects and toxicities, personnel to maintain close and regular contact with patients, and emergency access to psychiatrists and addiction counsellors. These programs are best funded by global or envelope funding so that resources can be appropriately allocated and can adapt to changing priorities. In the prison setting, there is a need for increased health care funding and supervision to establish realistic harm reduction strategies and addiction treatment plans for HCV/HIV co-infections. Provincial financing of drugs for treatment needs continual re-evaluation as new data emerge, so that patients expected to benefit from treatment have access to and financial coverage of needed therapies.

\section{Natural history}

\section{RESEARCH PRIORITIES}

- What is the natural history of HCV in HIV patients treated with HAART? Does HAART change the rate of progression of fibrosis? Does a normal ALT level exclude the progression of $\mathrm{HCV}$ ? Is the predictive value of a normal or near-normal liver biopsy in the co-infected patient similar to that of the HCV-positive, HIV-negative patient?

- What is the incidence of HCV-related mortality in those with HIV?

- What is the effect of alcohol use on the progression of liver disease in co-infected patients? What impact does addiction counselling and/or treatment have on this progression?

\section{Treatment issues}

- Should either HIV or HCV be treated first, or should both be treated simultaneously?

- What is the natural history and mechanism of liver abnormalities in the co-infected patient taking HAART?

- What impact does addiction counselling and/or treatment have on the adherence to, tolerance of and efficacy of treatment for viral infections?

- What are the in vivo correlates for the inhibition of phosphorylation by ribavirin and NRTI?

- What is the best marker to evaluate the response to therapy in co-infected patients? Is there an early marker of nonresponse to spare the toxicity and the cost of longer term therapy?

- Are there any significant drug interactions between the antiviral agents used to treat HIV and $\mathrm{HCV}$, and the pharmaceuticals used to treat substance-related disorders, such as methadone, buphenorphine, antabuse, naltrexone, bupropion and acamprosate?

- Can substance users with controlled addictions be managed for HCV without the risk of reinfection?

- Is directly observed therapy effective for HIV and HCV?
- Should HIV therapy for the co-infected patient include or spare protease inhibitors?

- What is the proper dose of ribavirin for the co-infected patient?

- Is the rate of long term, sustained response to HCV in the co-infected patient similar to that of the HIV-negative patient?

- In the co-infected patient, what is the optimal duration of anti-HCV treatment to obtain maximal responses without excessive toxicity? What are the predictors of response to treatment virologically, immunologically, clinically or behaviourally?

- Is liver transplantation an appropriate treatment for decompensated liver disease caused by HCV in a patient with stable HIV infection?

- What are the immunological and virological changes in either HIV or HCV associated with co-infection? How are these affected by treatment?

- Can these guidelines improve the management of the co-infected patient?

\section{REFERENCES}

1. Health Canada. The Canadian Guide to Clinical Preventative Health Care. Ottawa: The Canadian Task Force on the Periodic Health Examination, Minister of Supply and Services, 1994:xxxvii.

2. Health Canada. HIV and AIDS in Canada: Surveillance Report to December 31, 1999. Division of HIV/AIDS Surveillance, Bureau of HIV/AIDS, STD and TB, Laboratory Center for Disease Control. Ottawa: Minister of Public Works and Government Services, 2000.

3. Health Canada. HIV/AIDS Epi-update - HIV/AIDS among injection drug users in Canada. Ottawa: Laboratory Centre for Disease Control, 2000.

4. Elliot CJ, Blanchard JF, Dinner K, et al. The Winnipeg Injection Drug Epidemiology (WIDE) study. Can J Infect Dis 1999;10(Suppl B):C341. (Abst)

5. Ford P, Pearson M, Stevenson T, et al. HIV, hepatitis C and risk behavior in a Canadian medium security federal penitentiary. Q J Med 2000;93:113-9.

6. Enger C, Graham N, Peng Y, et al. Survival from early, intermediate, and late stages of HIV infection. JAMA 1996;275:1329-34.

7. Palella F Jr, Delaney KM, Moorman AC, et al. Declining morbidity and mortality among patients with advanced human immunodeficiency virus infection. N Engl J Med 1998;338:853-60.

8. Moore RD, Chaisson RE. Natural history of HIV infection in the era of combination antiretroviral therapy. AIDS 1999;13:1933-42.

9. Hogg RS, Yip B, Kully C, et al. Improved survival among HIV-infected patients after the initiation of triple-drug antiretroviral regimens. CMAJ 1999;160:659-65.

10. Detels R, Munoz A, McFarlane G, et al, for the Multicenter AIDS cohort study investigators. Effectiveness of potent antiretroviral therapy on time to AIDS and death in men with known HIV infection duration. JAMA 1998;280:1497-503.

11. Mocroft A, Vella S, Benfield TL, et al, for the EurosIDA Study group. Changing patterns of mortality across Europe in patients infected with HIV-1. Lancet 1988;352:1725-30.

12. Gulick RM, Mellors JW, Havlir D, et al. Treatment with indinavir, zidovudine, and lamivudine in adults with human immunodeficiency virus infection and prior antiretroviral therapy. N Engl J Med 1997;337:734-9.

13. Notermans DW, Jurriaans S, de Wolf F, et al. Decrease of HIV-1 RNA levels in lymphoid tissue and peripheral blood 
during treatment with ritonavir, lamivudine and zidovudine. AIDS 1998;12:167-73.

14. Montaner JSG, Reiss P, Cooper D, et al. A randomized double-blind trial comparing combinations of nevirapine, didanosine, and zidovudine for HIV-infected patients, the INCAS trial. JAMA 1998;279:930-7.

15. Staszewski S, Morales-Ramirez J, Tashima K, et al. Efavirenz plus zidovudine and lamivudine, efavirenz plus indinavir and indinavir plus zidovudine and lamivudine in the treatment of HIV-1 infection in adults. N Engl J Med 1999;341:1865-73.

16. Staszewski S, Keiser P, Gathe J, et al. Comparison of antiviral response with abacavir/combivir to indinavir/combivir in therapy-naïve adults at 48 weeks. 39th Interscience Conference on Antimicrobial Agents and Chemotherapy. San Francisco, September, 1999. (Abst)

17. Mehta S, Moore RD, Graham NHM. Potential factors affecting adherence with HIV therapy. AIDS 1997;11:1665-70.

18. Schacker T, Little S, Connick E, et al. Rapid accumulation of human immunodeficiency virus in lymphatic tissue reservoirs during acute and early HIV infection: Implications for timing of antiretroviral therapy. J Infect Dis 2000:181:354-7.

19. Carpenter CC, Cooper DA, Fischl MA, et al. Antiretroviral therapy in adults updated recommendations of the International AIDS Society - USA Panel. JAMA 2000;283:381-91.

20. Fauci AS, Bartlett JG, Goosby EP, Smith MD. Panel on clinical practices for treatment of HIV infection. Guidelines for the use of antiretroviral agents in HIV-infected adults and adolescents. MMWR Morb Mortal Wkly Rep 1998;47:42-82.

21. Rachlis AR, Zarowny DP, for the Canadian HIV Trials Network Working Group. Guidelines for antiretroviral therapy for HIV infection. CMAJ 1998;158:496-505.

22. Volberding P. Evidence-based recommendation on the management of HIV/AIDS: An experts' consensus meeting to develop treatment guidelines for developed nations. J Acquir Immune Defic Syndr Hum Retrovirol 1999;20:1-17.

23. Deeks SG, Grant RM, Beatty GW, et al. Activity of a ritonavir plus saquinavir-containing regimen in patients with virologic evidence of indinavir or ritonavir failure. AIDS 1998;12:F97-102.

24. Tebas P, Patick AK, Kane EM, et al. Virologic responses to a ritonavir-saquinavir-containing regimen in patients who had previously failed nelfinavir. AIDS 1999;13:F23-8.

25. Thomas DL, Zenilman JM, Alter H, et al. Sexual transmission of hepatitis $\mathrm{C}$ virus among patients attending sexually transmitted diseases clinics in Baltimore an analysis of 309 sex partners. J Infect Dis 1995; 171:768-75.

26. Gibb DM, Goodall RL, Dunn DT, et al. Mother to child transmission of hepatitis $C$ virus: evidence for preventable peripartum transmission. Lancet 2000;356:904-7.

27. Ramis R, Hogg R, Krahn MD, Preiksaitis JK, Sherman M. Estimating the number of blood transfusion recipients infected by hepatitis C virus in Canada, 1960-85, and 1990-92. Ottawa: Health Canada, June 1998.

28. Vogt M, Lang T, Frosner G, et al. Prevalence and clinical outcome of hepatitis $\mathrm{C}$ infection in children who underwent cardiac surgery before the implementation of blood-donor screening. N Engl J Med 1999;341:866-70.

29. Kenny-Walsh E. Clinical outcomes after hepatitis $\mathrm{C}$ infection from contaminated anti-D immune globulin. N Engl J Med 1999;340:1228-33.

30. Kiyosawa K, Tahaks E, Sodeyama T, Fumata S. Natural history of hepatitis C. Intervirology 1994;37:101-7.

31. Fattovich G, Giustina G, Degos F, et al. Morbidity and mortality in compensated cirrhosis type $\mathrm{C}$ : a retrospective follow-up study of 384 patients. Gastroenterology 1997;112:463-72.

32. Hu KQ, Tong MJ. The long term outcomes of patients with compensated hepatitis $C$ virus-related cirrhosis and history of parental exposure in the United States. Hepatology 1999:29:1311-6.

33. Poynard T, Bedossa P, Opolon P. Natural history of liver fibrosis progression in patients with chronic hepatitis C. Lancet 1997;349:825-32.

34. Benhamou Y, Bochet MD, Martino V, et al. Liver fibrosis progression in human immunodeficiency virus and hepatitis $C$ virus coinfected patients. The MULTIVIRC group. Hepatology 1999;30:1054-7.

35. Canadian Association for Study of the Liver (CASL) Consensus Conference Rappoteur Group. Canadian Consensus Conference on the Management of Viral Hepatitis. Can J Gastroenterol 2000;14(Suppl B):5B-20B.

36. Bedossa P, Poynard T, for the METAVIR Cooperative Study Group. An algorithm for the grading of activity in chronic hepatitis C. Hepatology 1996;24:289-93.

37. McHutchison J, Gordon S, Schiff E, et al. Interferon alfa $2 \mathrm{~b}$ alone or in combination with ribavirin as initial treatment for chronic hepatitis C. N Engl J Med 1998;339:1485-92.

38. Poynard T, Marcellin P, Lee S, et al. Randomized trial of interferon alpha $2 \mathrm{~b}$ plus ribavirin for 48 weeks or for 24 weeks versus interferon alpha $2 b$ plus placebo for 48 weeks for treatment of chronic infection with hepatitis $C$ virus. Lancet 1998;352:1426-32.

39. Davis G, Poynard T, Esteban-Mur R, et al. Durability of viral response to interferon alone or in combination with oral ribavirin in patients with chronic hepatitis C. Hepatology 1999;30:570A. (Abst)

40. Marcellin P, Boyer N, Gervais A, et al. Long-term histologic improvement and loss of detectable intrahepatic HCV RNA in patients with chronic hepatitis $\mathrm{C}$ and sustained response to interferon- $\alpha$ therapy. Ann Intern Med 1997;127:875-81.

41. Camma C, DiMarco V, Lo Iacono O, et al. Long-term course of interferon treated chronic hepatitis C. J Hepatol 1998;38:531-7.

42. Lau D, Kleiner DE, Ghany MG, et al. 10 year follow-up after interferon - a therapy for chronic hepatitis C. Hepatology 1998;28:1121-7.

43. Yoshida H, Shiratori Y, Moriyami M, et al. Interferon therapy reduces the risk of hepatocellular carcinoma: national surveillance program of cirrhotic and non-cirrhotic patients with chronic hepatitis $C$ in Japan. Ann Intern Med 1999;131:174-81.

44. Bonkovsky H, Woolley M, the Consensus Interferon Study Group. Reduction of health-related quality of life in chronic hepatitis $\mathrm{C}$ and improvement with interferon therapy. Hepatology 1999;29:264-70.

45. Ware JE, Bayliss M, Mannocchia M, Davis G, the International Hepatitis Interventional Therapy Group. Health related quality of life in chronic hepatitis C: impact of disease and treatment response. Hepatology 1999;30:550-5.

46. Sherman KE, Freeman S, Harrison S, Andron L. Prevalence of antibody to hepatitis $C$ virus in patients infected with the human immunodeficiency virus. J Infect Dis 1991;163:414-5.

47. Martin P, Di Bisceglie AM, Kassianides C, Lisker-Melman M, Hoofnagle JH. Rapidly progressive non-A, non-B hepatitis in patients with human immunodeficiency virus infection. Gastroenterology 1989;97:1559-61.

48. Sanchez-Quijano A, Andreu J, Gavilan F, et al. Influence of human immunodeficiency virus type I infection on natural course of chronic parenterally acquired hepatitis C. Eur J Clin Microbial Infect Dis 1995;14:949-53.

49. Soto B, Sanchez-Quijano A, Rodrigo L, et al. Human immunodeficiency virus infection modifies the natural history of chronic parenterally-acquired hepatitis $C$ with an unusually rapid progression to cirrhosis. J Hepatol 1997;26:1-5.

50. Darby S, Ewart D, Giangrande P, et al. Mortality from liver cancer and liver disease in haemophiliac men and boys in UK given blood products contaminated with hepatitis C. Lancet 1997;350:1425-31.

51. Colin JF, Cuzais-Hatem D, Loriot MA, et al. Influence of human immunodeficiency virus infection on chronic hepatitis B in homosexual men. Hepatology 1999;29:1306-10.

52. Allory Y, Charlotte F, Benhamou Y, et al. Impact of human immunodeficiency virus infection on the histological features of chronic hepatitis C: A case-control study. The MULTIVIRC group. Hum Pathol 2000;31:69-74.

53. Romeo R, Rumi MG, Donato MF, et al. Hepatitis C is more 
severe in drug users with human immunodeficiency virus infection. J Viral Hepat 2000;7:297-301.

54. Staples CT, Rimland D, Dudas D. Hepatitis C in the Human Immunodeficiency Virus Atlanta Veterans Affairs Medical Center Cohort Study (HAVACS): the effect of coinfection on survival. Clin Infect Dis 1999;29:150-4.

55. Spinetti A, Puito M, Donato F, et al. Increase of liver related in hospital mortality in a cohort of Italian seropositives after introduction of HAART: role of hepatitis virus coinfections. Durban, South Africa: XIII International AIDS Conference, July, 2000. (Abst)

56. Sulkowski MS, Thomas DL, Chaisson RE, Moore RD. Hepatotoxicity associated with antiretroviral therapy in adults infected with human immunodeficiency virus and the role of hepatitis C or B virus infection. JAMA 2000;283;74-9.

57. Hauser PM, Blanc DS, Bille J, Nahimana A, Francioli P. The impact of co-infection with hepatitis $C$ virus and HIV on the tolerability of antiretroviral therapy. J Acquir Immune Defic Syndr 2000;14:463-4.

58. Rutschmann OT, Negro F, Hirschel B, Hadengue A, Anwar D, Perrin LH. Impact of treatment with human immunodeficiency virus (HIV) protease inhibitors on hepatitis $\mathrm{C}$ viremia in patients coinfected with HIV. J Infect Dis 1998;177:783-5.

59. Perez-Olmeda M, Garcia-Saramego J, Soraino V. Hepatitis C viraemia in HIV-HCV co-infected patients having immune restoration with highly active antiretroviral therapy. AIDS 2000;14:212.

60. Moatti JP, Carrieri MP, Spire B, Gastaut JA, Cassuto JP, Moreau J. Adherence to HAART in French HIV-infected injecting drug users: the contribution of buprenorphine drug maintenance treatment. The Manif 2000 study group. AIDS 2000;14:151-5.

61. Loguercio C, Di Pierro M, Di Marino MP, et al. Drinking habits of subjects with hepatitis $\mathrm{C}$ virus-related chronic liver disease prevalence and effect on clinical, virological and pathological aspects. Alcohol 2000;35:296-301.

62. Khan KN, Yatsuhashi H. Effect of alcohol consumption on the progression of hepatitis $\mathrm{C}$ virus infection and risk of hepatocellular carcinoma in Japanese patients. Alcohol 2000;35:286-95.

63. Thomas DL, Astemborski J, Rai RM, et al. The natural history of hepatitis $\mathrm{C}$ virus infection: host, viral, and environmental factors. JAMA 2000;284:450-6.

64. Thio CL, Nolt KR, Astemborski J, et al. Screening for hepatitis $C$ virus in human immunodeficiency virus infected individuals. J Clin Microbiol 2000;38:575-7.

65. Expert Working Group on HIV Testing. Counseling Guidelines for HIV Testing. Ottawa: Canadian Medical Association, 1995.

66. Sees KL, Delucchi KL, Masson C, et al. Methadone maintenance vs 180-day psychosocially enriched detoxification for treatment of opioid dependence: a randomized controlled trial. JAMA 2000;283:1303-10.

67. US Public Health Service and Infectious Diseases Society of America. 1999 USPHS/IDSA guidelines for the prevention of opportunistic infections in persons infected with human immunodeficiency virus. MMWR Morb Mortal Wkly Rep 1999:48:1-66.

68. Reichard O, Yun ZB, Sonnerborg A, Weiland O. Hepatitis C viral RNA titers in serum prior to, during, and after oral treatment with ribavirin for chronic hepatitis C. J Med Virol 1993;41:99-102.

69. Zeuzem S, Feinman SV, Rasenack J, et al. Peginterferon alfa-2a in patients with chronic hepatitis C. N Engl J Med 2000;343:1666-72.

70. Heathcote EJ, Shiffman ML, Cooksley G, et al. Peginterferon alfa-2a in patients with chronic hepatitis $\mathrm{C}$ and cirrhosis N Engl J Med 2000;343:1673-80.

71. Glue P, Rouzier-Panis $\mathrm{R}$, Raffanel $\mathrm{C}$, et al. A dose ranging study of pegylated interferon alfa-2b and ribavirin in chronic hepatitis C. Hepatology 2000;32:647-53.

72. Heathcote EJ. Issues regarding the antiviral therapy of subjects with chronic hepatitis C. Semin Liver Dis 2000;20:185-99.

73. McCormick SE, Goodman ZP, Maydonovich CL, Sjorgren MH. Evaluation of liver histology, ALT elevation and HCV RNA titre in patients with chronic hepatitis C. Am J Gastroenterol 1996;91:1516-22.

74. Proti C, Stati T, Magcini A. Serum HCV RNA titre does not predict the severity of liver damage in HCV cases with normal aminotransferase levels. Liver 1999;19:104-9.

75. Sharry MG, Chau TM, Sandoz-Pescador R, Urdea M, Lok AS. Correlation between serum HCV RNA and aminotransferase levels in patients with chronic HCV infection. Dig Dis Sci 1996;41:2213-8.

76. Luo JC, Hwang SJ, Lai CR, et al. Relationship between serum aminotransferase levels, liver histology and virological status in patients with chronic hepatitis $\mathrm{C}$ in Taiwan. J Gastroenterol Hepatol 1998;13:685-90.

77. Schneiderman D, Arenson D, Cello J, Margaretten W, Weber T. Hepatic disease in patients with the acquired immune deficiency syndrome. Hepatology 1987;7:925-30.

78. Poles M, Dieterich D, Schwarz E, et al. Liver biopsy findings in 501 patients infected with human immunodeficiency virus (HIV). J Acquir Immune Defic Syndr Hum Retrovirol 1996;11:170-7.

79. Aledort LM, Levine PH, Hilgartner M, et al. A study of liver biopsies and liver diseases among hemophiliacs. Blood 1985;66:367-72.

80. Preston FE, Dusheiko G, Lee GA, Ludlam CA, Giangrande PLF. Guidelines on the diagnosis and management of chronic liver disease in hemophilia. Haemophilia 1995;1:42-4.

81. Wong VS, Baglin T, Beacham E, Wight DDG, Petrik J, Alexander GJM. The role of liver biopsy in haemophiliacs infected with the hepatitis $\mathrm{C}$ virus. Br J Haematol 1997;97:343-7.

82. Wong JB, Poynard T, Ling MH, Albrecht JK, Pauker SG. Cost effectiveness of 24 or 48 weeks of interferon treatment alpha$2 \mathrm{~b}$ alone or with ribavirin as initial treatment of chronic hepatitis C. Am J Gastroenterol 2000;95:1524-30.

83. Koff RS. Outcomes of costs of care in hepatitis C: combination therapy scores again. Am J Gastroenterol 2000;95:1392-3.

84. Garcia-Tsao G, Boyer J. Outpatient liver biopsy: How safe is it? Ann Intern Med 1993;118:150-3.

85. Piccinino F, Sagnelli E, Pasquale G, et al. Complications following percutaneous liver biopsy: A multicenter retrospective study on 68,276 biopsies. J Hepatol 1986;2:165-73.

86. Weiss K. Safety profile of interferon alpha therapy. Semin Oncol 1998;25(1 Suppl):9-13.

87. Maddrey W. Safety of combination interferon alfa-2b/ribavirin therapy in chronic hepatitis C-relapsed and treatment naïve patients. Semin Liver Dis 1999;19:67-75.

88. Boyer N, Marcellin P, Degott C, et al. Recombinant interferon alpha for chronic hepatitis $\mathrm{C}$ in patients positive for antibody to human immunodeficiency virus. J Infect Dis 1992;165:723-6.

89. Marriott E, Navas S, del Romero J, et al. Treatment with recombinant alpha interferon of chronic hepatitis $C$ in antiHIV positive patients. J Med Virol 1993;40:107-11.

90. Soriano V, Garcia-Samaniego J, Bravo R, et al, and the Hepatitis-HIV Spanish Study Group. Interferon $\alpha$ for the treatment of chronic hepatitis $C$ in patients infected with human immunodeficiency virus. Clin Infect Dis 1996;23:585-91.

91. Laundau A, Batisse D, Van Huyen JPD, et al. Efficacy and safety of combination therapy with interferon-alpha-2b and ribavirin for chronic hepatitis $\mathrm{C}$ in HIV-infected patients. AIDS 2000; $14: 839-44$

92. Causse X, Payen JL, Izopet J, Babany G, Saint Marc Girardin MF and the French Multicenter Study Group. Does HIV-infection influence the response of chronic hepatitis $C$ to interferon treatment? A French Multicenter prospective study. J Hepatol 2000;32:1003-10.

93. Ikeda K, Saitoh S, Suzuki Y, Kobayashi M, et al. Disease progression and hepatocellular carcinogenesis in patients with chronic viral hepatitis: A prospective observation of 2215 patients. J Hepatol 1998;23:1334-40.

94. Yano M, Kumada H, Kage $M$, et al. The long-term pathological evolution of chronic hepatitis C. Hepatology 1996;23:1334-40.

95. Schiffman M, Hofmann C, Contos M, et al. A randomized controlled trial of maintenance hepatitis interferon therapy for patients with chronic $\mathrm{C}$ virus and persistent viremia. Gastroenterology 1999;117:1164-72.

96. Baba M, Pauwels R, Balzarini J, Herewijn P, de Clercq E, 
Desmyter J. Ribavirin antagonizes inhibitory effectsof pyrimidine 2'3'-dideoxynucleosides but enhances inhibitory effects of purine 2'3'-dideoxynucleosides on replication of human immunodeficiency virus infection in vitro. Antimicrob Agents Chemother 1987;31:1613-7.

97. Vogt MW, Hartshorn KL, Furman PA, et al. Ribavirin antagonizes the effect of azithymidine on HIV replication. Science 1987;235:1376-9.

98. Zydelberg H, Benhamou Y, Lagneaux JL, et al. Safety and efficacy of interferon-ribavirin combination therapy in HCVHIV coinfected subjects: an early report. Gut 2000;47:694-7.

99. Brosgart C, Mitchell TF, Coleman RL, Dyner T, Stephenson KE, Abrams DI. Clinical experience and choice of drug therapy for human immunodeficiency virus disease. Clin Infect Dis 1999;28:14-22.

100. Volberding PA. Improving the outcomes of care for patients with human immunodeficiency virus infection. $\mathrm{N}$ Engl J Med 1996;334:729-31. 


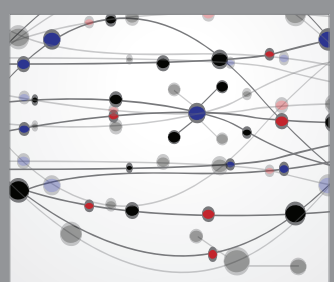

The Scientific World Journal
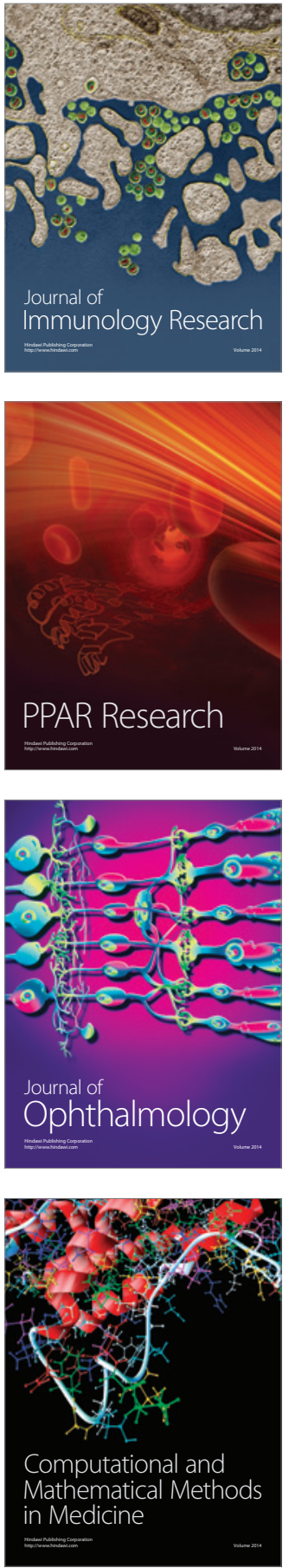

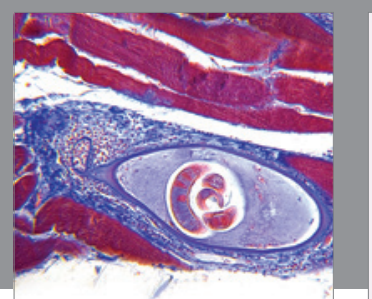

Gastroenterology Research and Practice

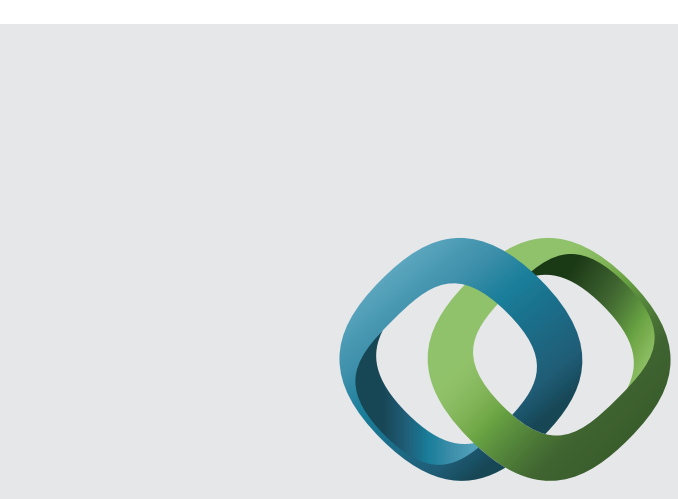

\section{Hindawi}

Submit your manuscripts at

http://www.hindawi.com
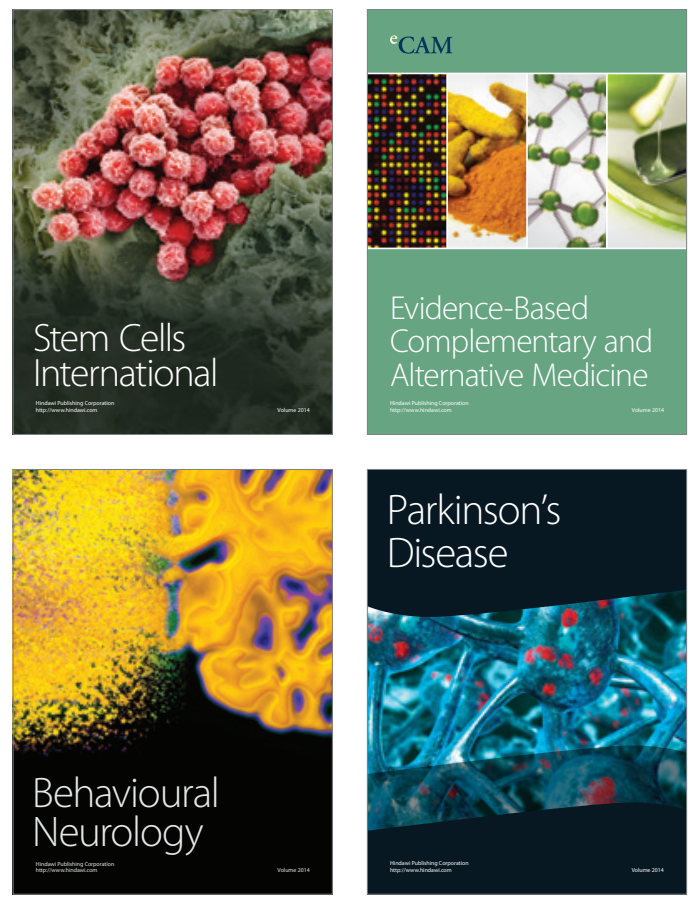
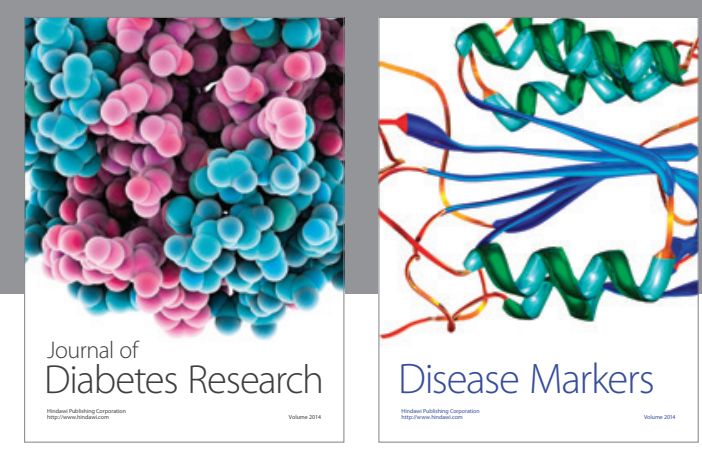

Disease Markers
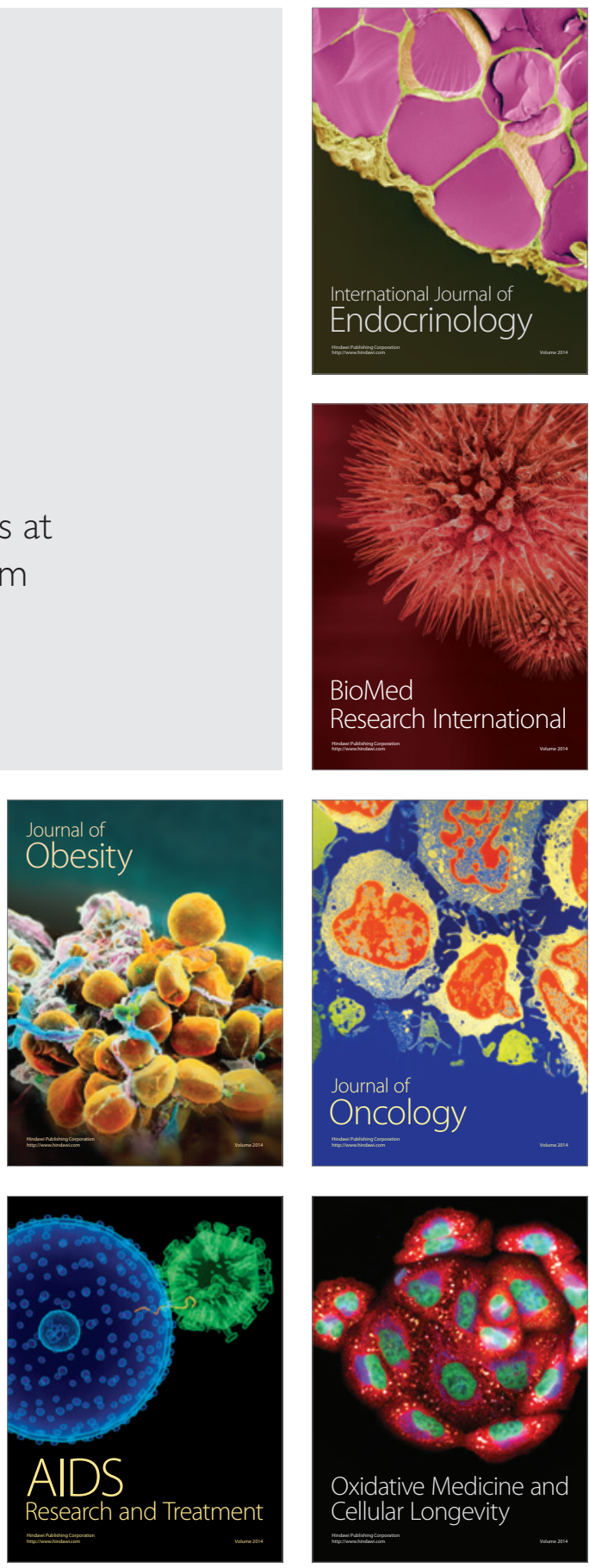